建 設省土木研究所

同

同
正員 栗 林 栄 一

同○岩崎敏男

同辻勝成

\title{
まえがを
}

地震応答スペクトルは、地震動が構造物に与える動的な影響を測る一つの指標として広く用いられ ている。地震応答スペクトルを用いた耐震計算法は1942 年Biotによってはじめて提案され、柔 構造に対する合理的な耐震設計の端緒が開かれた。その後 1953 年に Housnerらは、数多くの地震 動記録を用いて、減衰効果を考虑に入れた応答スペクトルを計算し、1959年には、Housner は 平均スペクトル曲線を提案した。

一方、わが国においても、1955 年に高橋は応答スペクトルの計算を試みており、また 1965 年には高田らは、わが国で得られた多数の強震記録を用いて一連の応答スペクトルの計算を行い、 水平動 20 成分から平均応答スペクトル曲線を提案した。高田らが提案した平均応答スペクトル曲線 は、わが国における多数の地震動の性質を包含するるのとして、道路橋などの土木構造物の地震応答 解析に使用されると共に、本州四国連絡橋の耐震設計指針に反映された。このように最近では地震応 答スペクトルが、実施設計に取り入れられるまでに至ってきている。またでく最近では片山拈よび 林らによって、地震応答スペクトルの特性に及ぼす、地震・地盤などの各種の条件の影響が論じら れている。

本小文に和いては、わが国で起こった、比較的大をい地震による水平方向の地震加速度記録 44 成 分（２０ｇ０工昆）の地震応答スペクトルを計算し、地震および地盤の条件から各種に分類し、グル ープどとに平均化するととによって、スペクトル曲線の特性に及添す、地震のマグニチュ一ド、最大 加速度、震央距離および地盤条件の影響を検討している。この結果から、地盤条件を 4 種に分類した 場合について、各地盤ごとの平均スペクトル（１９７０）を提案している。

1. 地震応答スペクトルの計算法

この研究において用いた、地震応答スペクトルの計算法を概述する。線型なげね・粘性減衰をもつ 1 自由度の質点系が、地震動変位 Z ( t)をらけた場合の運動方程式は、周知のでとく次式で表わされる。

$$
\mathrm{m} \ddot{\mathrm{y}}+\mathrm{c} \dot{\mathrm{y}}+\mathrm{ky}=-\mathrm{m} \ddot{\mathrm{z}}(\mathrm{t})
$$

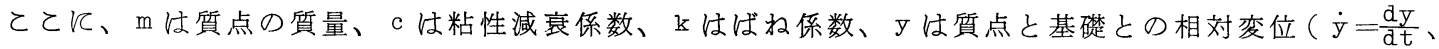
$\ddot{y}=\frac{d^{2} y}{d t^{2}}$ 人 $\ddot{z}(t)$ は地震動の加速度、tは時刻である。

式(1)の解y（時刻tにおける相対変位）は、つぎのDuhame工積分で与えられる。

$$
y=-\frac{1}{p \sqrt{1-h^{2}}} \int_{0}^{t} \ddot{z}(\tau) e^{-p h}(t-\tau) \sin p \sqrt{1-h^{2}}(t-\tau) d \tau
$$

乙と、 $\mathrm{p}=\sqrt{\mathrm{k} / \mathrm{m}}($ 非減衰固有円振動数; 固有周期 $\mathrm{T}=2 \pi / \mathrm{p}) 、 \mathrm{~h}=\frac{\mathrm{c}}{2 \sqrt{\mathrm{mk}}}($ 減衰定数)、 $\tau$ は時刻に 関する積分変数である。

Housner の定義に従らと、変位スペクトルS- 速度スペクトルSv、絶対加速度スペクトルSA 


$$
\begin{aligned}
S_{D}= & y_{\max }=\frac{1}{p \sqrt{1-h^{2}}}\left[S_{0}^{t} \ddot{z}(\tau) e^{-p h(t-\tau)}\right. \\
& \left.\quad \sin p \sqrt{1-h^{2}(t-\tau) d \tau}\right]_{\max } \\
S_{V}= & \left(\frac{2 \pi}{T}\right) S_{D} \\
S_{A}= & \left(\frac{2 \pi}{T}\right)^{2} S_{D}
\end{aligned}
$$

で表わされ、それぞれ変位、速度およ び加速度の単位を有している。スペク トルを無次元的に表示するすのとして、 次式で定義される加速度応答倍率 $\beta$ (加速度比、動的係数、復元力比など ともいわれる)のスペクトルがある。

$$
\beta=\frac{\mathrm{S}_{A}}{\ddot{Z}_{\max }}=\frac{\mathrm{kS}_{\mathrm{D}}}{\mathrm{m}_{\ddot{Z}_{\max }}}
$$

この $\beta$ ースペクトルには、地震加速度 の大きさが直接的には影響しないため、 多数のスペクトル間の平均值がとれる といら利点がある。以下では、地震お よび地盤の各種の条件によって、 $\beta$ スペクトルが、平均的にどのように変 化するかを検討する。

\section{2. 解析に用いた地震記録}

解析の対象としたのは44成分の地 震記録であり、最近わが国で起てった 比較的大をい地震を対象とし、地盤上 に設置されたS MAC型をたはDC型の 強震計による加速度記録である。数多 くある強震記録の中から、この44成 分を選出した基準としては、マグニチ ュードが 5 程度以上、最大加速度が

\begin{tabular}{|c|c|c|c|c|c|c|c|}
\hline \multirow{2}{*}{\multicolumn{2}{|c|}{ CLASS IFICATION }} & \multirow{2}{*}{ DEFINITION } & \multirow{2}{*}{ 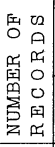 } & \multicolumn{3}{|c|}{ AVERAGE VALUES } & \multirow{2}{*}{ 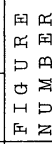 } \\
\hline & & & & $\ddot{z}_{\max }(\operatorname{gals})$ & $\mathrm{M}$ & $\Delta(\mathrm{K} m)$ & \\
\hline T $O T A$ & $\mathrm{~L}$ & & 44 & 116.8 & 6.3 & 84 & 1 \\
\hline \multirow{4}{*}{$\begin{array}{c}\text { MAGN I T UDE } \\
(M)\end{array}$} & MAG 1 & $M=4.8 \sim 5.5$ & 13 & 111.5 & 5.1 & 40 & \multirow{4}{*}{3} \\
\hline & MAG2 & $5.5 \sim 6.5$ & 12 & 72.6 & 6.1 & 37 & \\
\hline & MAG 3 & $6.5 \sim 7.5$ & 9 & 178.3 & 6.9 & 107 & \\
\hline & MAG 4 & $7.5 \sim 7.9$ & 10 & 121.3 & 7.7 & 176 & \\
\hline \multirow{5}{*}{$\begin{array}{c}\text { ACCELERATI ON } \\
\left(\check{Z}_{\max }\right)\end{array}$} & $\operatorname{ACC} 1$ & $\ddot{Z}_{\max }=20 \sim 50 \mathrm{glas}$ & 10 & 38.4 & 6.2 & 86 & \multirow{5}{*}{4} \\
\hline & $\mathrm{ACC} 2$ & $50 \sim 75$ & 10 & 60.1 & 6.2 & 64 & \\
\hline & $\mathrm{ACC} 3$ & $75 \sim 120$ & 9 & 92.6 & 6.3 & 91 & \\
\hline & $\operatorname{ACC} 4$ & $120 \sim 200$ & 9 & 163.2 & 6.5 & 124 & \\
\hline & $\operatorname{ACC} 5$ & $200 \sim 438$ & 6 & 308.6 & 6.3 & 42 & \\
\hline \multirow{3}{*}{$\begin{array}{l}\text { EPICENTRAL } \\
\text { DISTANCE } \\
(\Delta)\end{array}$} & DIS 1 & $\Delta=5 \sim 20 \mathrm{Km}$ & 15 & 156.6 & 5.6 & 11 & \multirow{3}{*}{5} \\
\hline & DIS 2 & $20 \sim 120$ & 16 & 106.4 & 6.4 & 67 & \\
\hline & DIS3 & $120 \sim 322$ & 13 & 83.9 & 7.0 & 189 & \\
\hline \multirow{4}{*}{ 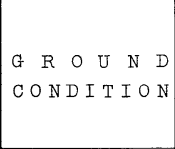 } & GR 1 & ROCK & 8 & 59.7 & 5.7 & 61 & \multirow{4}{*}{6} \\
\hline & aR 2 & DILLUVI UM & 12 & 104.9 & 6.0 & 88 & \\
\hline & GR 3 & ALUUVIUM 1 (STIFF) & 10 & 94.3 & 6.6 & 59 & \\
\hline & GR 4 & ALUUVIUM 2 (SOFT) & 14 & 175.7 & 6.7 & 89 & \\
\hline \multirow{3}{*}{ 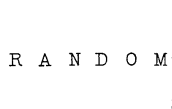 } & RAN 1 & & 14 & 103.0 & 6.3 & 93 & \multirow{3}{*}{7} \\
\hline & RAN 2 & & 15 & 108.5 & 6.2 & 87 & \\
\hline & RAN 3 & & 15 & 137.8 & 6.4 & 73 & \\
\hline
\end{tabular}

$20 \mathrm{gaI}$ 以上、さら反各種の分類を行 った場合に、グループ間の資料数に大 差がないととなどを配慮した。また流
TABLE 1 CLASSIFICATION OF 44 RECORDS
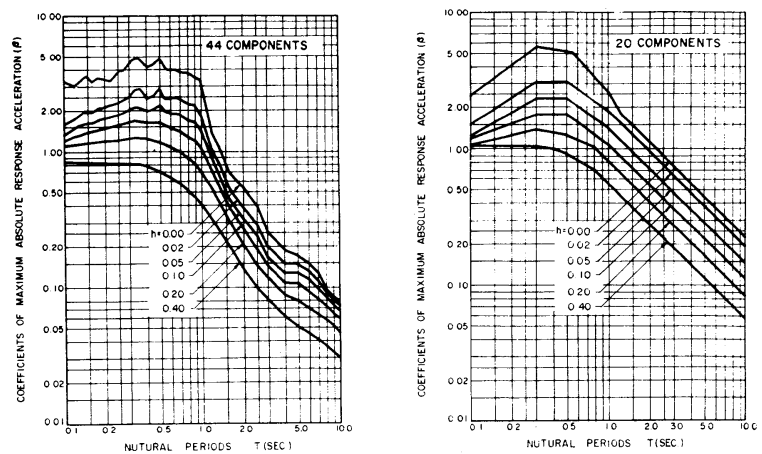

FIG 1 AVERAGE SPECTRA(1970) IG 2 AVERAGE SPECTRA(1964)

動化現象や大さい地変が観察された地点での記録は除外している。

3. 影響因子による分類と平均スペクトル

表 1 は4 4 成分の記録に関する、分類の種類を示している。地震応答スペクトルに及注す影響因子 として、こてではマグニチュード、最大加速度、震央距離および地盤条件の4 種を考え、とれらにつ らて3〜5グループに分類した。ててで、地盤条件の分類別けは次の目安によっている。

G R 1 : 岩盤または岩盤までの表層の厚さが $3 m$ 程度以下の場合 
G R 2 : 洪積層

G R 3 : 沖積層で G R 4 より良好な 地盤。

G R 4:厚々沖積層で、しか子表層 $10 \mathrm{~m}$ 以上飞わたって $\mathrm{N}$ 值が 10

程度以下である比較的軟弱な地盤。

44 成分全体の平均スペクトルを図 1 に示している。また図2 は高田ら が提案した平均スペクトル(1964) である。次に表 1 の各グループについ て減衰定数 $h=0.05$ の場合の平均応答 スペクトルを図 $3 〜 6$ 亿示す。以上の 他、44といら成分数がこのような細 分類ごとの平均をとる上に適当である かの判断資料とするため、4 4 成分を 無作為に3グループに分類し、それぞ れの平均をとってみたのが図 7 である。 この図から、3 者が㴗良好な一致を 示しているので、44成分を用いての 検討が有意義であるといえよう。

4. 全体の平均スペクトル

図 2 および 3 の比較から、今回の44 成分全体の平均スペクトル(1970) は20成分の平均スペクトル(1964) に非常によく近似しているが、全体的 スレベルがやや低下しているととが判 る。レベル低下の原因としては、今回 の平均では、資料数が前回の 2 倍以上 と多いとと、各種条件の地震記録が质 济均等飞含まれているとと、大加速度 の記録が多くなったとと等が考えられ
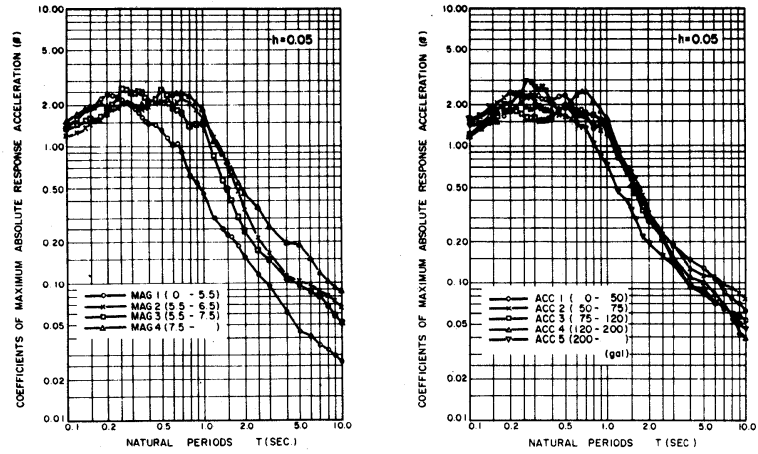

FIG 3 INFLUENCE OF MAGNITUDE

FIG 4 INFLUHNCE OF ACCETHRRATION
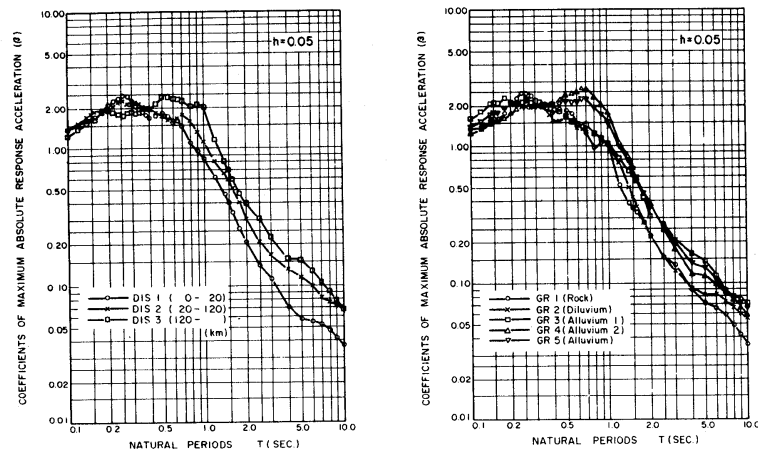

FIG 6 INFLUENCE OF GROUND CONDITION EPICENTRAL DISTANCE

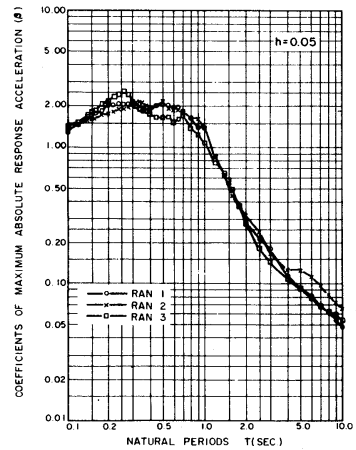

FIG 7 RANDOM SELECTION

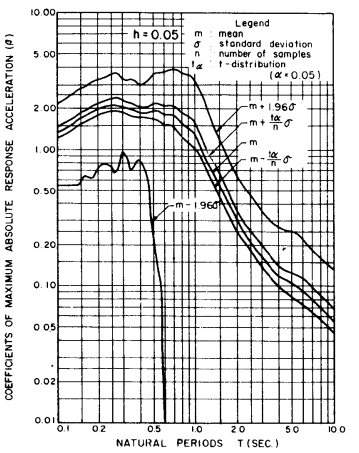

FIG 8 DEVIATION OF AVERAGE SPECTRA

る。なお図 8 は資料のバラッキを示した一例であり、この種の平均には、かなりのバラッキが伴らも のであるととを示している。

5. 地震応答スペクトルに及卞す各種因子の影響

まずマグニチュードの影響は図 3 から、マグニチュードが大をい地震では、 $\beta$ 值が大をくなる傾向 がらかがわれる。この傾向は長周期に対してはっきりと現われる。加速度の影響を示す図4 からは、 
特に明確な傾向は見出しにくいが、周 期 1 秒前後におらて、2008 a 工上上 の大加速度に対する $\beta$ 值が他と比較し てやや低下しているととが注目される。 震央距離の影響を示す図 5 からは、0.5 秒程度以上の長周期に対して、震央距 離が大きいほど、 $\beta$ 值が大をくなって らる。次に地盤条件の影響を示す図 6 から 0.5 秒程度以上の長周期に対して は軟弱な地盤ほど $\beta$ 值が大きくなる傾

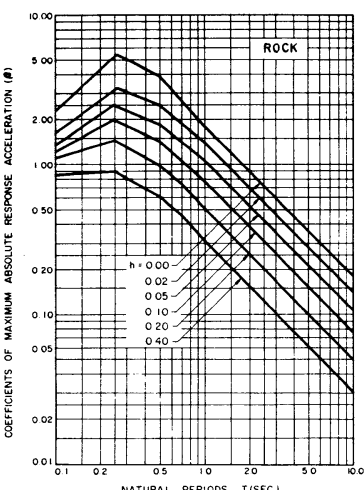
natural periods tisec,

FIG 9 AVERAGE SPECTRA FOR ROCK

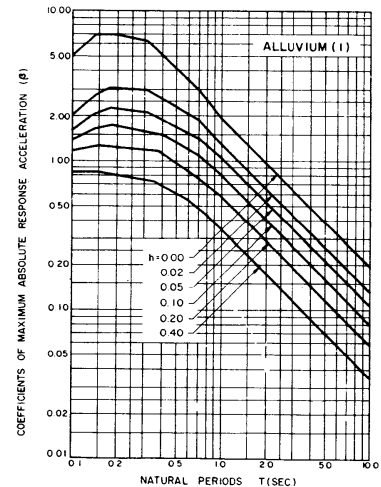

FIG 11 AVERAGE SPECTRA FOR STIFF ALLUVIUM

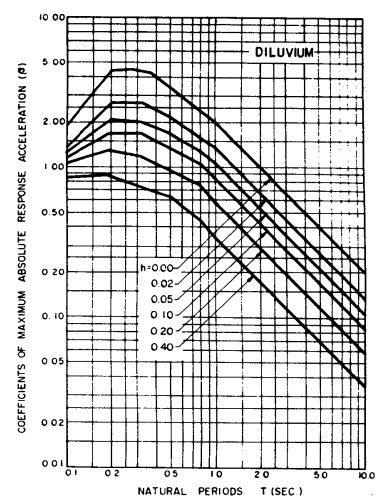

FIG 10 AVERAGE SPECTRA FOR DILLUVIUM

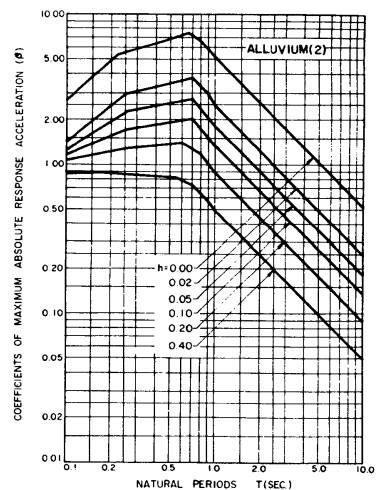

FIG 12 AVERAGE SPECTRA FOR SOFT ALLUVIUM 的に判定されらるものである。とのよ

うな背景を考虑して、地盤条件別の標準スペクトルを示したのが、図9〜12である。これらの図は、 図6およびこれに類するスペクトルを基本にして、細から凸凹は平滑化し、4グループを医等間 隔の差を設け、さらに長周期に対しては、 $\beta$ 值が両対数紙上で 45 の直線で低下する（速度スペク トル一定）といら仮説のもとに、作成したものである。

7. 結語

44 成分の地震記録を解析し、地震応答スペクトル（加速度応答倍率 $\beta$ ）に与える各種因子の影響 を検討して、比較的長周期の構造物に対して、下記の傾向があるととが判明した。

1) マグニチュードの大をい地震に対しては、 $\beta$ が大をい。

2）２００ｇa工を越すような大加速度では、 $\beta$ は低下する。

3）震央距離が大きい汪ど、 $\beta$ は大きい。

4）硬い地盤ほど $\beta$ が小さく、軟かい地盤ほど $\beta$ が大をい。 これらの性質を明らかにするとともに、実用の便を考慮した、各種地盤条件別の標準スペクトル

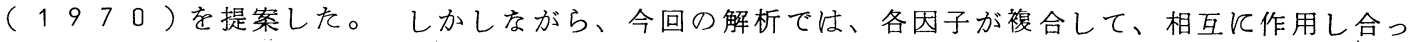
ているととが考えられる。今後さらに強震時の資料が增大するのを待って、他の条件は出来る限り 合致させた上で、ある特定の因子の影響を浮き彫りしていく事が必要となると考えられる。 